\title{
The Impact of Cross-Cultural Background Knowledge upon Iranian EFL Students' Productive Skills
}

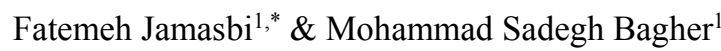 \\ ${ }^{1}$ Shiraz Azad University, Iran \\ *Correspondence: Shiraz Azad University, Iran. E-mail: ftmjamasbi@gmail.com
}

Received: March 9, 2017

Accepted: March 14, 2017 Online Published: February 29, 2017

doi:10.5430/wjel.v7n1p20

URL: https://doi.org/10.5430/wjel.v7n1p20

\begin{abstract}
Teaching culture has been considered important in foreign language instruction for almost a century. In this study the literature behind Cultural Schema Theory was reviewed and the practicality of applying this theory into the EFL classroom and its effect on the EFL students' productive skills (writing and speaking) were observed. This study includes two phases. First, a learning phase in which the treatment group was exposed to a variety of materials of different cultural issues. Second, a test phase in which a pre and post-test of speaking and writing were given to both control and experimental groups to determine any differences in their writing and speaking performance. And at the end of the treatment a semi-structured interview was used to know the experimental group's opinion about different cultural issues that were discussed during the term in their EFL class. The data was subjected to the statistical procedure of $t$-test and the results of this study indicated that not only all the students of experimental group outperformed the students of control group in their speaking and writing performance but also according to the semi-structure interview the students of experimental group had a positive reaction towards the integration of culture into the classroom context. The results showed that L2 learners may need to understand different aspects of the target culture better in order not only to speak and write accurately but also to interpret appropriately what they hear and to interact effectively with members of the target culture.
\end{abstract}

Keywords: productive skills; cultural background knowledge; writing performance; speaking performance

\section{Introduction}

In recent years, culture has become an increasingly important component of foreign language teaching. It is widely agreed that languages and culture are closely related, that knowledge of culture plays a major role in understanding a language. Ellis (1990) claims that students who are interested in the social and cultural life of the native country can learn a foreign language better than the other students, therefore students should be given support which will enable them to acquire the necessary cultural knowledge. Jiang (2000) contends that it is impossible to teach the target language without teaching the target culture. The students can be exposed to an empty frame of language if they do not learn cultural aspect of the target country. The integration of cultural schemata in L2 teaching is pivotal in the opinion of Buttjes and Byram (1991:24) who state that adding culture resembles the practice of an ethnographer seeking to describe the culture from the outside. They observed that : ... to separate language and culture teaching is to imply that a foreign language can be treated in the early stages as if it were self-contained and independent of other sociocultural phenomena. The consequence is that learners ... assume that the foreign language is an epiphenomenon of their own language, and that it refers to and embodies their existing understandings and interpretations of their own and foreign cultures. Where this arises ... the pupils cannot be said to be learning a foreign language in the proper sense, they are learning a codified version of their own (Rassmann, 2004). As a country with a relatively young population, Iran has become a center containing millions of young adults who are eagerly willing to learn different languages in order to communicate with the rest of the world. As an international language, English has been able to attract many young learners and serve as the cause of widespread growth of many language institutes. Recently, a more culturally-oriented teaching approach has been adopted in most English institutes due to the widespread use of books such as Summit and Interchange. However, the culture taught in such EFL classrooms has merely focused on topics such as traditions and holidays which are considered to be extremely 
artificial and has not amply received comparative treatment of the issue. The pedagogical approach used in English classrooms would be more effective if it focuses on the culturally appropriate and understandable context in which language is used, initially focusing on the source culture and then moving on to the target culture. So this study is an attempt to coordinate culture with other materials in class in order to enhance students' background knowledge and to explore the impact of this familiarity with cultural aspects of English on productive skills (speaking, writing) of Iranian learners of English.

\subsection{Research Questions}

The main research questions that this study focused on are as follows:

1. What is the effect of students' cultural background information on their speaking skill?

2. What is the effect of students' cultural background information on their writing skill?

\subsection{Significance of the Study}

In this study, the basic cultural information integrated systematically and completely in to the course content in order to improve learners' productive skills in a second language. Devoting the necessary amount of attention to integrating culture into EFL classrooms in Iran and fostering cross-cultural understanding which transcends the boundaries of linguistic forms and runs counter to a solipsistic world view can help foster the teaching as well as the learning process by shifting the attention from teaching grammar and textbook-bound structures of language to more cultural aspects of language teaching and learning.

\section{Literature Review}

\subsection{Schemata Theory}

Research on the psychological processes involved in comprehension clearly shows that what we understand of something is a function of our past experiences, our background knowledge, or what are sometimes more technically called our schemata (Bartlett, 1932; Rumelhart \& Ortony, 1977; Rumelhart, 1980). Schemata may be thought of as "interacting knowledge structures" (Rumelhart \& Ortony, 1977:100) stored in hierarchies in long term memory. Schemata have also been called the "building blocks of cognition" (Rumelhart, 1980). The schema concept is frequently attributed to Bartlett (1932) who posited that people's understanding and remembrance of events is shaped by their expectations or prior knowledge, and that these expectations are presented mentally in some sort of schematic fashion. Bartlett (1932) believed that our memory of discourse was not based on straight reproductions, but was constructive. This constructive process uses information from the encountered discourse, together with knowledge from past experience related to the discourse at hand to build a mental representation. The past experience, Bartlett argued, cannot be an accumulation of successive individuated events and experiences, it must be organized and made manageable -"the past operates as an organized mass rather than as a group of elements each of which retains its specific character (1932; p.197). What gives structure to that organized mass is the schema, which Bartlett did not propose as a form of arrangement, but as something which remained active and developing (1932; p.201). It is this active feature of discourse that leads to the constructive processes in memory (p. 249). Since Barlett's introduction of schema theory in 1932, there have been many further studies in both L1 and L2 contexts that have shown that human beings consistently overlay schemata on events to align those events with previously established patterns of experience, knowledge and belief (Swales, 1990). Schema reflecting how information is presented can also be culturally determined. The most important implication of schema theory is the role of prior knowledge in processing. In order for learners to be able to effectively process information, their existing schemata related to the new content need to be activated.

\subsection{Background Knowledge and Schema}

Psychologists generally agree that the single most important cognitive variable influencing learning is the knowledge students bring with them to the learning task (Chastain, 1988). Stevens (1980) defines background knowledge quite simply as "... what one already knows about a subject... (p.151)." Biemans and Simons' (1996) definition of background is slightly more complex, "... (Background knowledge is) all knowledge learners have when entering a learning environment that is potentially relevant for acquiring new knowledge (p.6)." Background knowledge is a parent term for many more specific knowledge dimensions. Anderson and Cheng (1999a) defines these two terms, schema and background knowledge, as synonyms. 


\subsection{Cultural Schema}

Cultural Schema Theory (Nishida, 1999) explains the familiar and pre-acquainted knowledge one uses when entering a familiar situation in his/her own cultureCultural Schema Theory proposes that when we interact with members of the same culture in certain situations many times, or talk about certain information with them many times, cultural schemas are created and stored in our brain (Nishida, 1999). When one's cultural environment provides experiences to which every member of that culture is exposed, his/her experiences allow every member to acquire cultural schemata (Nishida, 1999). Bedir (1992) mentions cultural schema and he defines it as the background knowledge about cultural aspects of the language being learned. If a person is not equipped with the appropriate cultural schema, $\mathrm{s} /$ he may not be able to make sense of culturally unfamiliar situations (Malcolm \& Sharafian, 2002).

\subsection{Productive Skills (Speaking \& Writing)}

Like listening, reading, and writing, speaking is a process. Speakers use their background and linguistic knowledge to create a message that will be meaningful to the intended audience. Speakers activate relevant schemata from specific contexts to convey meaning for a definite purpose with an intended audience in mind (Chastain, 1988). To specify just what it means to be a competent speaker of a particular language, you first need a certain linguistic competence and then communicative competence (Warghaugh, 1986). Writing is a very important and useful language skill which plays a crucial role in today's world. While writing, one is carrying out a kind of information processing. In fact according to Chastain (1988), writing is a process of encoding messages or pairing meaning with letters of alphabet. Writing is also an active process in the sense that when a person writes on a topic, he or she uses his or her prior knowledge (both linguistic and world knowledge) and language proficiency including knowledge of vocabulary, grammar and writing mechanics. In order for the writers to communicate their ideas and fulfill their goals in a second language, they need to possess background knowledge of the topic about which they are going to write. This background knowledge includes cultural knowledge of the target society as well. As a consequence of using background knowledge, second language writers need to possess cultural background knowledge of the target society if they want to communicate appropriately when writing in that language. Both writing and speaking are productive language skills, and both involve the conversion of thoughts to messages in the language.

\section{Methodology}

\subsection{Design of the Study}

The present research applied both quantitative and qualitative analysis. The quantitative data was gathered based on the speaking and writing tests which were designed by the instructor of the study. This study which was a "pretest-posttest control- group design" benefited the use of SPSS and the data of this study was analyzed through the SPSS statistical package (version 16). The qualitative aspect of the present study was obtained via a semi-structured interview that was conducted after the treatment.

\subsection{Participants}

The participants were sampled from the same English proficiency level. They were 47 elementary students of English in two classes, learning English at Bahar language institute in Shiraz. All the students were native speakers of Persian. They were all female students ranging in age from 18 to 27. One of the classes was assigned to the experimental group $(\mathrm{N}=22)$ and the other one the control group $(\mathrm{N}=25)$. The participants were selected mainly based on their availability. The researcher was the instructor of the English course and the performer of the study.

\subsection{Instruments}

In this study, the instruments which were used to elicit and collect information were in the forms of one test of speaking and one test of writing which contained items that the students needed to activate their cultural background knowledge of the target language and each test was used both as a pre and post-test. The speaking test contained 19 items (see Appendix A). The items were divided into 5 categories and for both pre and post-tests of speaking the instructor asked just one item from each category; in other words, each student answered 4 or 5 questions in about 10 minutes. The writing test contained 10 items (see Appendix B) which for both pre and post-test the instructor selected 3 topics among those 10 items and asked the students to write about 2 of those topics in about 20 minutes (each writing task contained about 100 to120 words). The tests were constructed by the researcher and the quality of the items was also checked by the consulting advisor. In order to gather the required data, at first some different cultural issues were selected in accordance with the topics of Top Notch, 1B they were studying (see Appendix C). Those issues (both in written and spoken form) which were heavily culturally loaded were extracted from various 
reliable sources, such as some Internet sites (www.bbc.com/ www.cnn.com), TOEFL passages and other authentic sources such as Summit and Interchange series. These issues were just presented to the experimental group. The last instrument was a semi-structured interview in Persian used in order to investigate how the students who received the treatment actually thought about different cultural issues that were discussed during the term in their EFL class. 6 out of 22 students of experimental group participated in this interview. Due to their low level and in order to be able to discuss their viewpoints clearly, the interview was in Persian. The final step in qualitatively interpreting the data obtained via the semi-structured interviews was for the researcher herself to listen to audio of the ideas each student expressed and these ideas were then summarized and transferred to the body of the present study.

\subsection{Data Collection}

The data for this study was collected in three months during the fall term of 2012. As mentioned before, two classes were needed; one class was considered as the experimental group and the other one as the control group. At the beginning of the study, the writing and speaking tests were given to both groups as pretests to determine their equality in writing and speaking ability and to be sure that the two groups were homogeneous. Then the treatment group was exposed to a variety of materials of different cultural issues that were prepared before. The researcher incorporated cultural material into her teaching to make the students familiar with the culture of the language they were learning. During the course the researcher helped the students (experimental group) to recognize and appreciate the differences between the two cultures for the benefit of successfully combining form and meaning in language learning. The researcher used various strategies to put the cultural awareness into practice to establish an intercultural understanding in the classroom. By following the instruction that Seelye (1974) identified for language teachers to consider while teaching culture, the researcher was provided with a reference list in the process of selecting, collecting and compiling cultural materials. The activities that were mostly applied by the researcher in class (experimental class) were personalization activities and discussion activities. Discussion activities were organized around the elements of the target culture and personalization activities were run to invoke identification with the students' own realities. The researcher first stimulated the students to talk about their own lives as most students love talking about themselves. This way, they would be able to draw the differences between the target country and their own. Due to the low level of learners, the researcher used the benefits of activities such as simple surveys, and question and answer tasks. At the end of the treatment, the students in both groups received the test of writing and speaking again as post-tests to determine any differences in their writing and speaking performance.

\subsection{Data Analysis}

In order to analyze the data, SPSS software (version 16) was used to obtain descriptive and inferential statistics. In this study, to overcome subjectivity and biases in the application and interpretation of the scores and to reach a consensus on all scores of pre and post-test of speaking and writing, two raters- a colleague and the researcherevaluated the scores immediately after giving the tests and then by the researcher again after two weeks. An inter-rater reliability was calculated for each set of scores. In order to enhance the reliability of the scores the researcher and the second rater scored all the data and calculate reliability across $100 \%$ of the data set. The researcher kept the second rater selectively blind about what part of the data (pre or posttest) or for which group (experimental or control) she was scoring, in order to reduce the possibility of inadvertent coder biases. The researcher was trained for one session and she had two training sessions with the other rater and she explained about the goals of the study, how to use the scales, and provided opportunities and sample data for the rater to practice rating before she judged the actual data. The researcher again rescored all the data herself two weeks later to check for intra-rater reliability of the scores. So to determine inter and intra- rater reliability of both speaking and writing test scores, Pearson Correlation Coefficient was applied by using SPSS. In order to compare the performances of students in the experimental group with that of control group, four descriptive statistics were first run to ensure about the homogeneity of the groups and also about their performance on pre and post-tests. Besides, two independent samples $t$-tests were run; one on the speaking test and the other one on writing test. Furthermore, to see whether there was any difference between students' writing and speaking performances in their experimental and control group, four paired samples $t$-tests were conducted: two on the writing and speaking tests in the experimental group and the other two on the writing and speaking in the control group separately. At the end in order to see if there was any correlation between the speaking and writing performance of the experimental group after treatment, a correlation analysis was run.

\section{Results and Discussion}

In this study, to overcome subjectivity and biases in the application and interpretation of the scores and to reach a 
consensus on all scores of pre and post-test of speaking and writing, two raters- a colleague and the researcherevaluated the scores. To determine inter and intra- rater reliability of both speaking and writing test scores, Pearson Correlation Coefficient was applied by using SPSS.

Table 1. Inter-rater Reliability

\begin{tabular}{lcc}
\hline & "Experimental Group" & "Control Group" \\
\hline Speaking pre-test & $\mathrm{Sig} .=.000$ & $\mathrm{Sig} .=.000$ \\
& $\mathrm{r}=.979$ & $\mathrm{r}=.977$ \\
Speaking post-test & $\mathrm{Sig} .=.000$ & $\mathrm{Sig} .=.000$ \\
& $\mathrm{r}=.893$ & $\mathrm{r}=.969$ \\
Writing pre-test & $\mathrm{Sig} .=.000$ & $\mathrm{Sig} .=.000$ \\
& $\mathrm{r}=.986$ & $\mathrm{r}=.989$ \\
Writing post-test & $\mathrm{Sig} .=.000$ & $\mathrm{Sig} .=.000$ \\
& $\mathrm{r}=.989$ & $\mathrm{r}=.981$ \\
\hline
\end{tabular}

Table 1 gives the actual values of the Pearson correlation coefficients along with their p-values. The correlation coefficients for all sets of scores (except for Speaking post-test of experimental group) were above 0.90 and the p-values were 0.000 . Thus it can be concluded that the correlation coefficients were significant, that is, there were very high correlations between the researcher's scores and the second rater's.

Table 2. Intra-rater Reliability

\begin{tabular}{lcc}
\hline & "Experimental Group” & "Control Group” \\
\hline Speaking pre-test & $\mathrm{Sig} .=.000$ & $\mathrm{Sig} .=.000$ \\
& $\mathrm{r}=.984$ & $\mathrm{r}=.974$ \\
Speaking post-test & $\mathrm{Sig} .=.000$ & $\mathrm{Sig} .=.000$ \\
& $\mathrm{r}=.985$ & $\mathrm{r}=.966$ \\
Writing pre-test & $\mathrm{Sig} .=.000$ & $\mathrm{Sig} .=.000$ \\
& $\mathrm{r}=.986$ & $\mathrm{r}=.988$ \\
Writing post-test & $\mathrm{Sig} .=.000$ & $\mathrm{Sig} .=.000$ \\
& $\mathrm{r}=.978$ & $\mathrm{r}=.976$ \\
\hline
\end{tabular}

Table 2 shows that the correlation coefficients for all sets of scores were above 0.90 and the p-values were 0.000 . So the correlation coefficients were significant, that is, there were very high correlations between the two sets of scores that were rated by the researcher at two times.

\subsection{The Effect of Students' Cultural Background Knowledge on Their Speaking Skill}

In order to begin the study and to make sure that the two groups were homogeneous enough in their speaking performance prior to the study (in the first session of each class); a pretest was administered to both control and experimental groups. Each pretest was scored based on IELTS speaking criteria (see Appendix D) which were adopted from (www.examenglish.com/IELTS/IELTS-Speaking- MarkSchemes.htm) by the researcher and a second rater at the moment and by the researcher again after two weeks in order to be sure about the reliability of the test scores. The students' speaking skill as a whole was marked based on four separate scales:

1. Fluency and coherence,

2. Lexical resource,

3. Grammatical range and accuracy and

4. Pronunciation 
Each of these categories was awarded a score form $1-5$ and the total score (20) for each student was computed out of 100. According to Table 3 the mean of the experimental group $(M=50.91)$ in the speaking pretest is a bit higher than the mean of the control group $(\mathrm{M}=50.00)$ but the difference is very marginal. Based on the results of the independent sample $t$ - test there was no significant difference between control and experimental groups' speaking performance. As shown in Table 3, the result obtained from this statistical analysis revealed that the two groups did not differ significantly in their performance on their speaking pretest. $(\operatorname{sig}=.832, \mathrm{p}>0.05)$

Table 3. Descriptive Statistics and T-Test Results of Speaking Pretest

\begin{tabular}{lllllllc}
\hline & codes & $\mathrm{N}$ & Mean & SD & t & df & sig \\
\hline Speaking pretest & Exp. & 22 & 50.91 & 15.011 & \multirow{2}{*}{214} & \multirow{2}{*}{45} & \multirow{2}{*}{.832} \\
& Cont. & 25 & 50.00 & 14.142 & & & \\
\hline
\end{tabular}

After the treatment, in order to see if the two groups performed statistically different on their speaking skill, the raw scores obtained from the administration of the speaking posttest were subjected to an independent $t$ - test. Table 4 shows the descriptive statistics of the speaking posttest and illustrates that the difference between the control and the experimental group performance on speaking posttest is significant. $(\mathrm{Sig}=.001, \mathrm{p}<0.01)$. Therefore it can be stated that teaching cultural materials in the class and providing the students with culturally related supplementary materials, helped the students to build their cultural background knowledge and to activate and use this knowledge in their speaking performance.

Table 4. Descriptive Statistics and T-Test Results of Speaking Posttest

\begin{tabular}{llllcccc}
\hline & codes & N & Mean & SD & t & df & sig \\
\hline Speaking posttest & Exp. & 22 & 80.23 & 13.494 & \multirow{2}{*}{3.602} & \multirow{2}{*}{45} & \multirow{2}{*}{.001} \\
& Cont. & 25 & 67.40 & 10.909 & & & \\
\hline
\end{tabular}

\subsection{The Effect of Students' Cultural Background Knowledge on Their Writing Skill}

In order to see whether there is any difference between the two groups in their writing performance, at the beginning of the study, the writing pretest was administered to both groups. Each pretest was scored based on IELTS writing criteria (see Appendix E) which were adopted from (www.examenglish.comIELTS/IELTS-Writing-MarkSchemes.htm) by the researcher and a second rater at the moment and by the researcher again after two weeks in order to be sure about the reliability of the test and the scores. The students' writing skill as a whole was marked based on five separate scales:

1. Relevance (arguments, ideas and evidence)

2. Clarity and organization

3. Accurate spelling

4. Range of vocabulary and appropriateness

5. Range of sentence structures and accuracy

Each of these categories was awarded a score form $1-5$ and the total score (25) for each student was computed out of 100. The descriptive statistics of the writing pretest appear in Table 7. Having a look at Table 5, we can see that the mean of the experimental group $(\mathrm{M}=60.36)$ in the writing pretest is a bit higher than that of the control group $(\mathrm{M}=57.12)$, but the difference is very marginal. To obtain whether the two groups had a statistically different performance on the writing pretest, another independent sample $t$-test was run. Table 5 showing the result obtained from the statistical analysis reveales that the two groups did not differ significantly in their performance on the writing pretest. (Sig. $=.447, \mathrm{p}>0.05$ ) 
Table 5. Descriptive Statistics and T-Test Results of Writing Pretest

\begin{tabular}{lccccccc}
\hline & codes & N & Mean & SD & t & df & sig \\
\hline Writing posttest & Exp. & 22 & 60.36 & 13.741 & & & \\
& Cont. & 25 & 57.12 & 15.078 & .767 & 45 & .447 \\
\hline
\end{tabular}

After the treatment, in order to see if the two groups performed statistically different on their writing skill, they were given the writing posttest at the end of the term. Table 6 shows the descriptive statistics of the scores obtained from the test. The result of the independent $t$-test on writing posttest reveals that there is a statistically significant difference between students' performance on the posttest of writing. Similar to their speaking performance, the students' writing performance in the experimental group $(\mathrm{M}=76.91)$ outperformed those in the control group $(\mathrm{M}=$ 64.16). (Sig. $=.002, \mathrm{p}<0.01$ )

Table 6. Descriptive Statistics and T-Test Results of Writing Posttest

\begin{tabular}{cccccccc}
\hline & codes & N & Mean & SD & t & df & sig \\
\hline Writing posttest & Exp. & 22 & 76.91 & 15.014 & \multirow{2}{*}{3.249} & 45 & .002 \\
& Cont. & 25 & 64.16 & 11.859 & & & \\
\hline
\end{tabular}

Therefore it can be stated that teaching cultural materials in the class prompted students' performance on their writing skill. After being exposed with some cultural points of the target language (especially the United States), experimental group had a better performance in their both writing and speaking skills (productive skills).

\subsection{The Improvement of Experimental and Control Groups' Speaking Performance}

In order to compare the experimental and control groups' involvement in speaking performance two paired $t$-tests were run to see if any improvement occurred in the experimental and control groups' speaking performance from the beginning to the end of the term.

Table 7. Paired $t$-Tests on Experimental and Control Groups' Speaking Performance

\begin{tabular}{lccccc}
\hline Speaking performance & $\mathrm{M}$ & $\mathrm{SD}$ & $\mathrm{t}$ & $\mathrm{df}$ & Sig. \\
\hline Experimental group pretest posttest & -29.318 & 13.210 & -10.410 & 21 & .000 \\
Control group pretest posttest & -17.400 & 8.675 & -10.029 & 24 & .000 \\
\hline
\end{tabular}

According to the results of the first paired $t$-test related to the experimental group, shown in Table 7, there is a statistically significant difference between the experimental group's performance in their speaking pre and posttest (Sig. $=.000, \mathrm{p}<0.001)$. It can be concluded that the experimental group had an improvement in their speaking performance after the treatment. So, integrating culture with other materials in class improved students' performance in speaking. The results of the second paired $t$-test are related to the control group. The difference between the obtained means for the two pre and posttests of speaking in the control group is (-17.40) smaller than the difference between those for pre and posttest of speaking in the experimental group (-29.31). Although there is a statistically significant difference between pre and posttest of speaking in both groups (experimental and control groups), experimental group performed better in their speaking test.

\subsection{The Improvement of Experimental and Control Groups' Writing Performance}

In order to compare the experimental and control groups' involvement in writing performance two paired $t$-tests were run.

Table 8. Paired T-Tests on Experimental and Control Groups' Writing Performance

\begin{tabular}{lccccc}
\hline Writing performance & $\mathrm{M}$ & $\mathrm{SD}$ & $\mathrm{t}$ & $\mathrm{df}$ & Sig. \\
\hline Experimental group pretest posttest & -16.545 & 12.727 & -6.098 & 21 & .000 \\
Control group pretest posttest & -7.040 & 12.071 & -2.916 & 24 & .008 \\
\hline
\end{tabular}


According to the results of the first paired $t$-test related to the experimental group shown in Table 8 we can claim that there is a statistically significant difference in the writing performance between the pretest and posttest in the experimental group (Sig. $=.000, \mathrm{p}<0.001)$. It can be inferred that the students in the experimental group improved their writing performance after the treatment. The results of the second paired $t$-test are related to the control group. Although there is a statistically significant difference between pre and posttest of writing in control group ( $\mathrm{Sig}=.008$, $\mathrm{p}<.05$ ), the difference between the obtained means for the two pre and posttests of writing in the control group is $(-7.040)$ smaller than the difference between those for pre and posttest of writing in the experimental group (-16.545). So, experimental group performed much better in their writing test.

\subsection{The Relationship between the Experimental Groups' Improvement in Speaking and Writing Skill}

In a further analysis, in order to see if there is any correlation between the speaking and writing performance of the experimental group after treatment, a correlation analysis was run. Table 9 shows the mean and standard deviation of the obtained score.

Table 9. Descriptive Statistics of Posttests in Experimental Group

\begin{tabular}{lccc}
\hline & Mean & Std. Deviation & N \\
\hline Speaking posttest & 80.23 & 13.494 & 22 \\
Writing posttest & 76.91 & 15.014 & 22 \\
\hline
\end{tabular}

In Table 10, the Pearson correlation coefficient along with its $p$-value is shown. As it was expected from the benefits of using and activating cultural background knowledge in productive skills, there was a significant positive correlation between speaking and writing posttest. $(\mathrm{r}=.88, \mathrm{Sig}=.000, \mathrm{p}<.001)$

Table 10. Correlations of Speaking and Writing

\begin{tabular}{llrr}
\hline & & Speaking post & Writing post \\
\hline Speaking & Pearson Correlation & 1 & $.883^{* *}$ \\
posttest & Sig. (2-tailed) & 22 & .000 \\
& $\mathrm{~N}$ & $.883^{* *}$ & 22 \\
\multirow{2}{*}{ Writing posttest } & Pearson Correlation & .000 & 1 \\
& Sig. (2-tailed) & 22 & 22 \\
& $\mathrm{~N}$ & & \\
$* *$ &
\end{tabular}

So it can be concluded that there is a strong positive relationship between the participants' productive skills, that is, their speaking and writing skills. As Chastain (1998) and Brown (2007) maintain, the two skills have a lot of features in common and their development go through relatively the same processes.

\section{Results of the Semi-Structured Interview}

\subsection{The Usefulness of Discussing Cultural Issues in Class}

The first item was asked to find out whether discussing on different cultural issues in class was useful to them and how. All agreed that those issues were useful due to helping them to:

a) Understand the world of the native speakers better.

b) Be able to communicate appropriately in different settings.

c) Communicate appropriately with English- speaking friends and when traveling to an English speaking country. 
d) Learn to use models appropriate to the culture and avoid offending the hosts with wrong behavior, dress, etc.

e) Become aware of the differences between cultures and get motivated to interact with members of the target culture.

\subsection{The Effect of Cultural Issues on Their Motivation}

The second item assessed whether the cultural issues discussed had any impact on their motivation to study English language. All agreed that the issues had positive effect on their motivation to continue studying English language in a way that:

a) They enjoyed the feeling of acquiring knowledge about English community and their way of life.

b) They got a satisfied feeling when they learned new things about a different culture.

c) They demonstrated a willingness to interact with members of the host culture.

d) They felt more confident in speaking English.

\subsection{Students' Reactions towards Cultural Differences}

The third item dealt with their reactions towards understanding the differences between the target culture and their own.

a) They learned to develop the ability to show flexibility in terms of cultural behavior when interacting with the members of the host culture.

b) They learned from the host culture and their language.

c) They stated that by contrasting aspects of the host culture and language with that of their own, they got motivated to interact with members of the host culture and helped them not to have negative reactions to differences between the two cultures.

\subsection{The Effect of Cultural Issues on Their Language Skills}

The fourth item focused on whether having information about the target culture contributed to any of the language skills of participants. All 6 students gave affirmative answers to this item. Regarding the skill improved most, all the participants (100\%) expressed their views by suggesting that their speaking skill was significantly improved. Half of the participants agreed that reading and writing skills came next. Just 2 of them agreed on listening improvement. Since teaching cultural issues was discussion based and the participants discussed cultural topics in the target language, the participants mostly practiced speaking.

a) They became efficient speakers and writers.

b) They expanded their vocabulary knowledge.

The results of this study are discussed based on the two research questions:

\section{What is the effect of students' cultural background information on their speaking skill?}

Prior to the study a pretest of speaking was given to both experimental and control groups. The result of the independent sample $t$ - test which was conducted to investigate the difference between the performances of the two groups showed that there was no significant difference between the control $(M=50.00)$ and experimental groups $(M$ $=50.91)^{\prime}$ speaking performance $(\mathrm{sig}=.832, \mathrm{p}>0.05)$.

After the treatment and exposing the experimental group to a variety of materials of different cultural issues, the same test of speaking (this time as a posttest) was given to both groups again. The mean of the experimental group $(M=80.23)$ in the speaking posttest was higher than that of the control group $(M=67.40)$ and the difference between the control and the experimental group performance on speaking posttest was significant $(\mathrm{Sig}=.001, \mathrm{p}<$ $0.05)$. Although there was a statistically significant difference between pre and posttest of speaking in both groups (experimental and control groups) and both had improvements in their speaking skill due to the fact that both studied Top Notch 1B during the term, experimental group performed better in their speaking test especially they got higher scores because of their richer lexical resources (they had wide enough vocabulary resources to discussed topics with appropriate choices) and their fluency (topics were developed coherently and appropriately). The difference between the obtained means for the two pre and posttests of speaking in the control group is (-17.40) smaller than the difference between those for pre and posttest of speaking in the experimental group (-29.31). So it can be concluded that the experimental group had an improvement in their speaking performance after the treatment. The integration of 
cultural materials in the classroom had a positive impact on the students' speaking skill. Therefore The culture associations that are part of language, as well as the socio-cultural background of the participants in teaching and learning environments, ultimately affect how and how well the language is learnt (Albertini, 1993). In the speaking pre and posttests the participants were asked to apply their own background knowledge in order to answer the questions and the result of this study revealed that the students of control group failed to transfer their skills and strategies in their speaking because of a lack of vocabulary, linguistic and background knowledge in the target language. Since they did not have enough information about the target culture, they couldn't answer the speaking questions properly. In this study by integrating cultural materials, the natural environment was brought into the class. And these issues that were discussed in class provided an insider's view of the target culture and could help narrow the gap in attitude and social distance. In comparing the speaking performances of these two groups, I can surly say that the members of experimental group's discussion were richer and their explanations were more accurate. Based on the results of the semi-structured interview, the learners believed that the integration of culture into the classroom teaching syllabus could help them overcome any negative reaction they might have towards the target culture while giving them the opportunity to compare and contrast the cultural values of both languages and giving them the ability to cite a basic definition of culture. These learners also agreed that their motivation in acquiring the English language was either to travel abroad or develop strategies that would help them learn the target language and about the target culture. Finally, the learner participants agreed that the inclusion of intercultural discussions in the EFL classroom could help them learn the appropriate way to communicate with a native speaker in different contexts and gain the necessary motivation and confidence to interact with native speakers of the target language.

\section{What is the effect of students' cultural background information on their writing skill?}

At the beginning of the study a pretest of writing was given to both groups. The topics that they were asked to write about required them to have enough cultural background knowledge. So due to their lack of appropriate cultural schemata, the scores of both groups were not satisfactory. The differences between the writing performances of both groups were computed by using an independent sample $t$ - test. There was no significant difference between the control $(M=57.12)$ and experimental group $(M=60.36)$ writing performance (Sig. $=.447, p>0.05)$.

After the treatment and exposing the experimental group to a variety of materials of different cultural issues, the same test of writing (this time as a posttest) was given to both groups again. By integrating cultural schemata in L2 teaching in the class of experimental group and by building their cultural background knowledge, the researcher influenced their writing performance and the students of experimental group made significant improvements in their writing skill. By regarding the fact that the mean of the experimental group $(\mathrm{M}=76.91)$ in the writing posttest was higher than that of the control group $(\mathrm{M}=64.16)$ and the difference between the control and the experimental group performance on writing posttest was significant (Sig. $=.002, \mathrm{p}<0.01$ ). So having cultural background knowledge of the target language appears to positively contribute to the writing skill. The participants in the experimental group who were exposed to the cultural materials outperformed in their writing performances those who did not receive any treatment in the control group. These participants got higher scores in their writing due to giving clear and relevant ideas or information and appropriate and accurate vocabulary. The results of both paired sample $t$-tests revealed that there was a statistically significant difference between pre and posttest of writing in both experimental group (Sig. $=.000, \mathrm{p}<0.01)$ and control group ( $\mathrm{Sig}=.008, \mathrm{p}<.05)$. The difference between the obtained means for the two pre and post-tests of writing in the control group is (-7.040) smaller than the difference between those for pre and posttest of writing in the experimental group (-16.545). Therefore the integration of cultural materials in the classroom had a positive impact on the students' writing skill. So, the cultural background knowledge effect was strong. The group of students possessing cultural background knowledge outperformed the other group that lacked it in their writing performances. The results suggested that cultural background knowledge of the students helped them write better because of their better culturally familiarity with the topics.

Another fact that was found based on the result of the semi-structured interview that was mentioned before, was that the students of the experimental group felt better prepared to write about those topics because of taking part beforehand in the extended course of building cultural background knowledge through in- class sharing and discussion.

In order for the learners to communicate their ideas and fulfill their goals in a second language writing they need to possess background knowledge of the topics about which they are going to write. This background knowledge includes cultural knowledge of the target society as well. As a consequence of using background knowledge, EFL learners need to possess cultural background knowledge of the target society if they want to communicate appropriately when writing in that language. 
The results of this study are in line with the findings of Bedir (1992) who studied the relationship between culture and language. The results of this study are also in line with the findings of Bilal Gence and Erdogan Bada (2005) examined the effects of learning culture in four areas: 1. language skill 2. cultural awareness 3. attitude toward culture 4. contribution to the prospective teaching profession.

By the fact that language and culture are intricately interrelated with each other, it goes without saying that L2 teachers need to increase learners' sociolinguistic awareness involved in cultural norms in order to assist them in improving their L2 communicative performance. Learners' chances of experiencing cross-cultural miscommunication can thus be greatly reduced. Having high level of frustration and insecurity in many speaking classes, the students don't feel that they are learning to speak the language. The reason is due to their asking to talk about the topics that are not based on their experiences or due to their lack of background knowledge. Floyd and Carrell (1987) maintain that the ESL teacher must provide the student with appropriate schemata s/he is lacking, and must also teach the student how to build bridges between existing knowledge and new knowledge.

In the light of this research, teachers may be recommended to activate students' schema before writing and speaking activities. If a topic involves some cultural points that these points are different from the learners' own culture (in a situation when there are cultural differences between the target culture and the native culture) the teacher should provide cultural background knowledge. Having background knowledge is a key feature to the successful speaking and writing production. So, language learners willing to improve their speaking and writing skills should have greater exposure to target culture materials. Through having greater exposure to specific culturally- oriented materials language learners can improve their speaking and writing skills.

The results obtained from this study revealed that providing essential information about the target language culture and helping students to reach a cultural understanding to accompany their linguistic knowledge had a positive effect on their productive skills.

\section{References}

Albertini, J. (1993). Critical literacy, whole language, and the teaching of writing to deaf students: Who should dictate to whom?. Tesol Quarterly, 27(1), 59-73. https://doi.org/10.2307/3586951

Anderson, N. J., \& Cheng, X. (1999). Exploring second language reading: Issues and strategies (pp. 53-56). Boston, MA: Heinle \& Heinle.

Bartlett, F. C. (1932). Remembering. Cambridge: Cambridge University Press.

Bedir, H. (1992). Cultural significance in foreign language learning and teaching with special emphasis on reading comprehension through cultural schema. Unpublished masters' thesis, Adana: Çukurova University.

Biemans, H. J., \& Simons, P. R. J. (1996). Contact-2: a computer-assisted instructional strategy for promoting conceptual change. Instructional Science, 24(2), 157-176. https://doi.org/10.1007/BF00120487

Brown, H.D. (2007). Principles of language learning and teaching (5th ed.). White Plains, NY: Pearson Longman.

Buttjes, D., \& Byram, M. (Eds.). (1991). Mediating languages and cultures: Towards an intercultural theory of foreign language education (Vol. 60). Multilingual Matters.

Floyd, P., \& Carrell, P. L. (1987), Effects on ESL Reading of Teaching Cultural Content Schemata. Language Learning, 37, 89-108. https://doi.org/10.1111/j.1467-1770.1968.tb01313.x

Chastain, K. (1988). Developing second language skills. Theory and practice, 3.

Ellis, R. (1990). Understanding second language acquisition. OUP: Oxford.

Genc, B., \& Bada, E. (2005). Culture in language learning and teaching. The Reading Matrix, 5(1).

Jiang, W. (2000). The relationship between culture and language. ELT journal, 54(4), 328-334. https://doi.org/10.1093/elt/54.4.328

Malcolm, I. G., \& Sharifian, F. (2002). Aspects of Aboriginal English oral discourse: An application of cultural schema theory. Discourse Studies, 4(2), 169-181. https://doi.org/10.1177/14614456020040020301

Nishida, H. (1999). Cultural Schema Theory: In W.B. Gudykunst (Ed.), Theorizing About Intercultural Communication, (pp. 401-418). Thousand Oaks, CA: Sage Publications, Inc.

Rassmann, E. (2004). Taxi texts as reading material and a source of cultural schemata for L2 Zulu. Southern African 
Linguistics and Applied Language Studies, 22(3-4), 143-157. https://doi.org/10.2989/16073610409486367

Rumelhart, D. E. (1980). Schemata: the building blocks of cognition. Theoretical issues in reading and comprehension. BBRJ Sprio, \& WF Brewer.

Rumelhart, D. E., \& Ortany.A. (1977). The representation of knowledge in memory. In A.C. Anderson, R.J Spiro and W.E. Montague (eds.), Schooling and the Acquisition of knowledge. Hillsdale, NJ: Lawrence Erlbaum Associates.

Seelye, H. N. (1974). Teaching culture: Strategies for foreign language educators. National Textbook Company.

Stevens, K. C. (1980). The effect of background knowledge on the reading comprehension of ninth graders. Journal of reading behavior, 12(2), 151-154. https://doi.org/10.1080/10862968009547365

Swales, J. (1990). Genre analysis: English in academic and research settings. Cambridge University Press.

Warghaugh, R. (1986). An introduction to sociolinguistics. Oxford: Blackwell.

\section{Appendix A: Speaking Questions}

\section{Shopping Smart}

1. Why do you tip? /Is tipping a good idea or a bad one? Please compare the tipping custom in the U.S and in Iran?

2. How can you pay for things when you travel (cash, a traveler's check, an ATM card, a credit card...)? /Which one do you usually use? Why?

3. Do you usually bargain for a lower price? /Where is it OK to bargain?

4. Why do people use credit cards? /Where can they use it?

\section{Taking Transportation}

5. Talk about high speed passenger trains.

6. What kind of train and ticket will you choose if you travel by train? Why?

7. What is the train departure board for?

8. What is an overbooking?

9. What information do passengers get from airport announcement?

10. What are airport security rules? Do they drive you crazy? Why?

\section{Getting Away}

11. Why do people go on vacation? What activities do they do during it?

12. Name some travel services and say how to book them.

\section{Finding something to wear}

13. What are the advantages/ disadvantages of online shopping? How do people shop online?

14. Talk about different types of clothes (formal and informal) and the places people should wear them.

15. Talk about different attitudes about clothing? (liberal, conservative, anything goes) Which one do you agree on? Why?

16. Compare the way to number the floors in the U.K and U.S.?

\section{Staying in Shape}

17. Talk about junk food.

18. What personal questions can't you ask your colleague? Why?

19. Your friend is inviting you to a party. Decline her invitation.

\section{Appendix B: Writing Questions}

\section{Shopping Smart}

1. Name an English speaking country which tipping is customary there and specify where, how much and to whom you should tip.

2. Imagine you are taking a trip to an English -speaking country. Write how you pay for things and why. Do you bargain for a lower price? If yes, in which places? 
3. Why do people use credit cards? /Where can they use it?

\section{Taking Transportation}

4. Write about a trip that you had transportation problems and specify the means of transportation, destination, good memories and problems.

5. Write about your next trip and specify the place, kind of transportation, time of departure $\&$ arrival, activities during your trip.

\section{Getting Away}

6. Write about your vacation preferences.

- What's important to you in a vacation?

- What activities do you like to do during it?

7. Compare the travel services in Iran and another country and the way to book them.

\section{Finding something to wear}

8. What is online shopping? What are the advantages and disadvantages of it?

9. Write about different attitudes about clothing? (liberal, conservative, anything goes) Which one do you agree on? Why?

\section{Staying in Shape}

10. Write about junk food.

\section{Appendix C: The Titles of Cultural Issues}

\section{These topics are extracted from Top Notch $1 \mathrm{~B}$.}

1. Tipping (where, how, how much, to whom, why)

2. Different ways of paying for things (when you travel). Which one is more appropriate in different places? [traveler's check, credit cards, ATM cards, cash, ...]

3. Bargaining for a lower price. Where is it OK?

4. Credit cards. Which places accept them?

5. A.M. and P.M. [where a 12- hour clock is used] [where a 24- hour is used]

6. High speed passenger trains like bullet train

7. A departure schedule in an airport. The information it gives you.

8. How to buy tickets. Different types of tickets.

9. How to use the information of the train departure board?

10. Different travel services and how to book them

11. The meaning of "an overbooking"

12. Airport announcements

13. Transportation and transportation problems

14. Airport security rules

15. Vacation. Why to take a vacation? The activities people do on vacation (skydiving $\&$ hang gliding)

16. Vacation ads and how to choose a suitable vacation

17. Online shopping (advantages/ disadvantages) and how to shop online

18. Factors of choosing a place to shop for clothes

19. Clothing do's and don'ts

20. Different types of clothes (formal/informal) and the place to wear each of them

21. Different attitudes about clothing (liberal/ conservative/ anything goes)

22. The way to number the floors in the U.K. / U.S. and Canada.

23. How to decline an invitation in English

24. Asking personal questions (is it polite or not?)

25. Junk food 


\section{Appendix D: Marking of the oral exam}

\begin{tabular}{|c|c|c|c|c|c|}
\hline Students' names & $\begin{array}{c}\text { fluency, } \\
\text { coherence } \\
{[5]}\end{array}$ & $\begin{array}{c}\text { Lexical } \\
\text { resources } \\
{[5]}\end{array}$ & $\begin{array}{c}\text { Grammatical } \\
\text { range and } \\
\text { accuracy } \\
{[5]}\end{array}$ & $\begin{array}{c}\text { Pronunciation } \\
{[5]}\end{array}$ & $\begin{array}{l}\text { Total } \\
\text { [20] }\end{array}$ \\
\hline & & & & & \\
\hline & & & & & \\
\hline & & & & & \\
\hline & & & & & \\
\hline & & & & & \\
\hline & & & & & \\
\hline & & & & & \\
\hline & & & & & \\
\hline & & & & & \\
\hline & & & & & \\
\hline & & & & & \\
\hline & & & & & \\
\hline & & & & & \\
\hline & & & & & \\
\hline & & & & & \\
\hline & & & & & \\
\hline & & & & & \\
\hline & & & & & \\
\hline & & & & & \\
\hline & & & & & \\
\hline & & & & & \\
\hline & & & & & \\
\hline
\end{tabular}


Appendix E: Marking of the written exam

1. Poor 2.Good 3.Very good 4.Fair 5.Excellent

\begin{tabular}{|c|c|c|c|c|c|c|}
\hline Students' names & $\begin{array}{c}\text { Relevance } \\
\text { (arguments, } \\
\text { ideas and } \\
\text { evidence) } \\
{[5]}\end{array}$ & $\begin{array}{c}\begin{array}{c}\text { Clarity \& } \\
\text { organization }\end{array} \\
{[5]} \\
\end{array}$ & $\begin{array}{c}\begin{array}{c}\text { Accurate } \\
\text { spelling }\end{array} \\
\\
{[5]} \\
\end{array}$ & $\begin{array}{c}\text { Range of vocabulary } \\
\& \text { appropriateness } \\
{[5]}\end{array}$ & $\begin{array}{c}\text { Range of } \\
\text { sentence } \\
\text { structures \& } \\
\text { accuracy[5] }\end{array}$ & $\begin{array}{l}\text { Total } \\
{[25]} \\
\end{array}$ \\
\hline & & & & & & \\
\hline & & & & & & \\
\hline & & & & & & \\
\hline & & & & & & \\
\hline & & & & & & \\
\hline & & & & & & \\
\hline & & & & & & \\
\hline & & & & & & \\
\hline & & & & & & \\
\hline & & & & & & \\
\hline & & & & & & \\
\hline & & & & & & \\
\hline & & & & & & \\
\hline & & & & & & \\
\hline & & & & & & \\
\hline & & & & & & \\
\hline & & & & & & \\
\hline & & & & & & \\
\hline & & & & & & \\
\hline & & & & & & \\
\hline & & & & & & \\
\hline
\end{tabular}

